\title{
Níveis de fibra em detergente neutro em dietas para eqüinos ${ }^{1}$
}

\section{Auro César Braga ${ }^{2}$, Kleber Villela Araújo ${ }^{3}$, Gilberto Gonçalves Leite ${ }^{4}$, Alessandra Gimenez Mascarenhas $^{5}$}

\author{
1 Projeto financiado pelo CNPq. \\ ${ }^{2}$ Medico Veterinário Militar, Exército Brasileiro, Brasília-DF. \\ ${ }^{3}$ Zootecnista, Ministério da Agricultura, Brasília-DF. \\ ${ }^{4}$ Embrapa Cerrados, Brasília-DF. \\ ${ }^{5}$ Faculdade de Agronomia e Veterinária - FAVIUPIS.
}

RESUMO - Objetivou-se nesta pesquisa avaliar os efeitos de dois níveis de fibra em detergente neutro (FDN) da dieta (25 e 35\%), provenientes de duas proporções de volumoso/concentrado (50:50 e 60:40), sobre a digestibilidade dos nutrientes, o pH fecal e os parâmetros sangüíneos de lactato, glicose, uréia, creatinina e fosfatase alcalina, visando estabelecer os níveis mínimos e seguros de fibra em dietas para eqüinos. Utilizaram-se cinco eqüinos sem raça definida, com 6 a 8 anos de idade e peso médio de $300 \mathrm{~kg}$, alojados em gaiolas próprias para estudos de metabolismo. Os animais foram distribuídos em delineamento de quadrado latino $5 \times 5$, composto de cinco tratamentos (dois níveis de FDN, 25 e 35\%, duas relações volumoso:concentrado, 50:50 e 60:40, e uma dieta controle, com relação 50:50 volumoso:concentrado) e cinco períodos. Cada período experimental teve duração de 15 dias (10 de adaptação e 5 de coleta de fezes e sangue e determinação do pH fecal). Os níveis de FDN utilizados neste experimento (25 e 35\%) reduziram a digestibilidade dos componentes fibrosos (fração parede celular) da dieta, entretanto, não influenciaram os níveis sangüíneos de lactato, glicose, uréia, creatinina e fosfatase alcalina e o pH fecal. A dieta com 25\% de FDN promoveu alteração no teor plasmático de fibrinogênio, portanto, pode aumentar a predisposição dos animais a quadros de laminite e cólica.

Palavras-chave: digestibilidade, glicose, lactato

\section{Neutral detergent fiber levels in diet of equines}

\begin{abstract}
The objective of this research was to evaluate the effects of two levels of neutral detergent fiber (NDF) of the diet (25 and 35\%) from two forage to concentrate (50:50 and 60:40) ratio on nutrient digestibility, fecal pH and blood parameters as lactate, glucose, urea, creatinine, fibrinogen and alkaline phosphatase, to establish minimum and safe levels of fiber in equines diets. Five horses without defined race, with 6 to 8 years old and average $300 \mathrm{~kg} \mathrm{BW}$, were housing in metabolism cages. The animals were distributed to $5 \times 5$ Latin square design, composed of five diets (two levels of NDF, 25 and $35 \%$, two forage to concentrate ratio, 50:50 and 60:40, and a control diet, with 50:50 forage to concentrate ratio, and five periods. Each period lasted 15 days (10 of adaptation and 5 for collection of feces and blood and $\mathrm{pH}$ fecal determination). Neutral detergent fiber levels (25 and 35\%) reduced the fiber components digestibility (cell wall fraction) of the diet, however, did not influence the levels of blood parameters as lactate, glucose, urea, creatinine and alkaline phosphatase and fecal pH. Diet with $25 \%$ of NDF promoted change in fibrinogen plasma level, therefore, may increase the susceptibility of animals to colic and laminitis problems.
\end{abstract}

Key Words: digestibility, glucose, lactate

\section{Introdução}

Os eqüinos apresentam anatomia e fisiologia digestiva adaptada para se alimentarem exclusivamente de forragens (herbívoros). Qualquer programa de alimentação que negligencie os níveis de fibra na dieta pode ter conseqüências indesejáveis sobre a fisiologia digestiva destes animais (Pagan, 1996). A fibra, além de ser importante para manutenção da população de microrganismos desejáveis no intestino grosso, proporciona aos eqüinos o efeito psicológico da saciedade e produção de $\beta$ - endorfinas durante os movimentos de mastigação. A fermentação das fibras pelos microrganismos intestinais produz energia e previne a proliferação de outras bactérias, potencialmente patogênicas. Meyer et al. (1985) afirmaram que o conteúdo de fibras de um alimento afeta o tempo de alimentação, a 
quantidade de mastigação e o conteúdo de matéria seca do bolo alimentar ingerido. Portanto, comportamentos estereotipados em eqüinos estabulados podem ser reduzidos quando esses animais são alimentados com dietas contendo maior porcentagem de alimentos volumosos pelo fato de aumentar o tempo de ingestão e reduzir a ociosidade dos animais (Meyer, 1995). Segundo Pagan (1996), eqüinos necessitam de certo volume de alimento para sustentar função digestiva normal e, ao privá-los de alimentos volumosos, as curvaturas do intestino ficam propensas a torções e cólicas.

Cunha (1991) afirma que certa quantidade de fibras é necessária na dieta desses animais, mas a quantidade exata ainda não foi precisamente determinada, em razão das várias condições e dos estágios do ciclo de vida dos eqüinos. De acordo com esse autor, a necessidade mínima de ingestão de forragem é de 25 a 50\% da dieta total, com base na matéria seca.

Segundo Kline (1996), a dieta de eqüinos deve conter pelo menos $50 \%$ de forragem, embora alguns animais de alto desempenho tenham dificuldades de manter condição corporal adequada com esta limitação de alimento concentrado. Conforme descrito por Frape (1992), a porção de concentrado da ração diária pode conter de 0 a $50 \%$ e, excepcionalmente, poderá chegar a $75 \%$ da dieta. Pagan (1999) afirma que toda dieta de eqüinos deve ser constituída de pelo menos $25 \%$ de fibra (FDN).

Portanto, objetivou-se nesta pesquisa avaliar a influência de dois níveis de fibra em detergente neutro (25 e 35\%) provenientes de duas proporções de volumoso/ concentrado (50:50 e 60:40) na dieta de eqüinos sobre a digestibilidade dos nutrientes, os níveis bioquímicos séricos de glicose, lactato, uréia, creatinina, fibrinogênio e fosfatase alcalina e o $\mathrm{pH}$ fecal, visando estabelecer níveis mínimos e fisiologicamente seguros de fibra para esses animais.

\section{Material e Métodos}

A pesquisa foi realizada na Fazenda Água Limpa, pertencente à Universidade de Brasília (FAL/UnB), Distrito Federal. Foram utilizados cinco eqüinos sem raça definida, com 6 a 8 anos de idade e $311 \pm 4,8 ; 290 \pm 1,4 ; 319 \pm 10,1$; $265 \pm 28,1$; e $338 \pm 23,5 \mathrm{~kg}$, alojados individualmente em gaiolas próprias para estudos de metabolismo.

Como tratamentos, foram avaliados dois níveis de fibra em detergente neutro (FDN) na matéria seca da dieta total (25 e 35\%), de modo que cada nível obtido a partir de duas proporções de volumoso e concentrado (50:50 e $60: 40$ ). As dietas testadas foram comparadas a uma dieta controle, com relação volumoso:concentrado de 50:50
(45,36\% de FDN), conforme recomendado pelo NRC (1989) para eqüinos adultos.

Os animais foram distribuídos em delineamento do tipo quadrado latino $(5 \times 5)$, composto do peso dos animais e dos períodos (variáveis de controle). Durante 15 dias, cada animal recebeu uma dieta. Em seguida, todos foram mantidos por sete dias em descanso em pastagens, recebendo $3 \mathrm{~kg}$ de concentrado à base de milho e farelo de soja. Posteriormente, receberam as dietas experimentais em outra seqüência, durante 15 dias, até o quinto período. Cada período de 15 dias foi dividido em uma fase pré-experimental de 10 dias, para adaptação ao manejo das gaiolas e às dietas, e outra experimental de 5 dias, para coletas. Na fase de adaptação, os animais se exercitavam durante 60 minutos em uma área sem cobertura vegetal.

As dietas fornecidas aos animais foram compostas de feno de capim-tifton (Cynodum dactylon) picado e concentrado na forma física farelada (Tabela 1) e foram formuladas para atender $100 \%$ das exigências nutricionais de um eqüino adulto com peso médio de $300 \mathrm{~kg}$, segundo o NRC (1989). As rações foram formuladas para conter níveis eqüitativos de nutrientes, variando somente o teor de fibra; para isso, foi adicionado caulin (material inerte) e, com objetivo de ajustar a energia digestível, foi incluído óleo nas dietas com 35\% de FDN e na dieta controle. Foram fornecidas três refeições diárias (às 8, 13 e 17 h) e o volume de água no bebedouro foi completado nos mesmos horários. As amostras das dietas (5\% do total fornecido) foram obtidas três vezes ao dia, no momento do fornecimento, e armazenadas para posterior análise.

As fezes foram coletadas duas vezes ao dia (7 e $16 \mathrm{~h}$ ) e, em seguida, foram pesadas, homogeneizadas, amostradas (5\%), identificadas e armazenadas em sacos plásticos identificados a $-15^{\circ} \mathrm{C}$ para análises posteriores. As amostras diárias de fezes e de volumosos formaram, ao final dos períodos de coleta, uma amostra composta de fezes e outra de volumosos. As amostras de fezes e alimentos foram analisadas quanto aos teores de matéria seca, nitrogênio total, energia bruta, extrato etéreo, cinzas, cálcio e fósforo, segundo metodologia descrita por Silva (1990). As análises de fibra em detergente neutro e fibra em detergente ácido foram realizadas segundo metodologia descrita por Van Soest (1967) e Van Soest et al. (1991).

Nos dois dias finais de cada fase experimental, pela manhã, foi colhido sangue da veia jugular de cada eqüino, em jejum por 12 horas, para análise dos teores de glicose, lactato, uréia, creatinina, fibrinogênio e fosfatase alcalina. As amostras foram encaminhadas ao laboratório para análise segundo metodologia descrita por Kaneko (1989), em aparelho espectrofotômetro. $\mathrm{O}$ pH fecal foi determinado em 
Tabela 1 - Composição percentual e nutricional das dietas

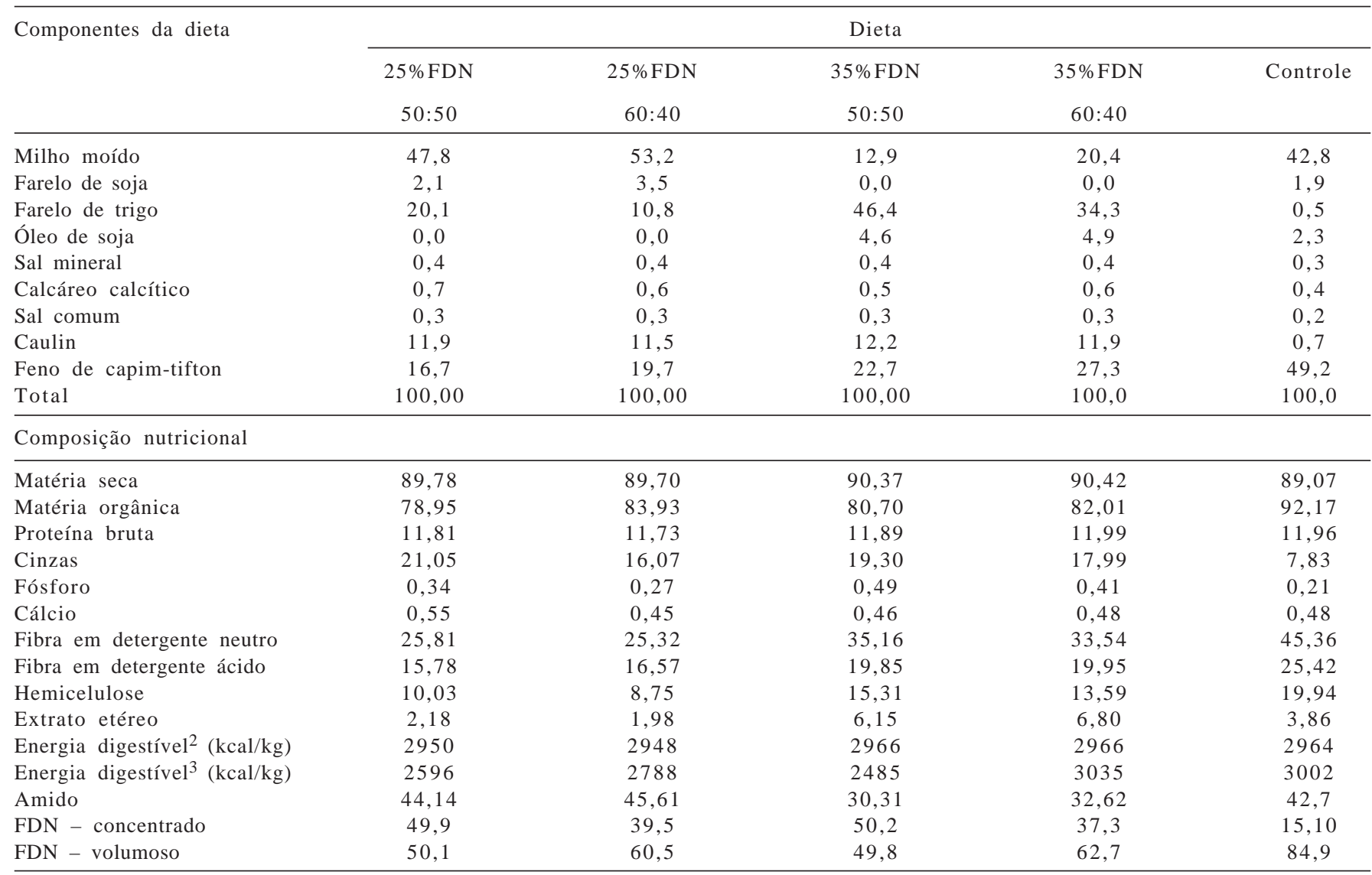

${ }^{1}$ Análises realizadas no Laboratório da Embrapa Cerrados, Brasília-DF.

2 Valores calculados com base na tabela do NRC (1989).

${ }^{3}$ Valores calculados com base nos resultados de digestibilidade encontrados nesta pesquisa.

amostras de fezes coletadas diretamente na ampola retal, no Laboratório de Nutrição Animal da FAL/UnB. Da amostra, foi retirada uma alíquota de $20 \mathrm{~g}$, que foi diluída em $100 \mathrm{~mL}$ de água destilada, homogeneizada, filtrada e analisada quanto ao $\mathrm{pH}$ em potenciômetro digital. Os animais foram examinados diariamente durante o período experimental e não apresentaram qualquer evidência de patologia.

Foram calculados os coeficientes de digestibilidade de matéria seca, proteína bruta, energia bruta, matéria orgânica, extrato etéreo, fibra em detergente neutro, fibra em detergente ácido e hemicelulose. Os resultados dos coeficientes de digestibilidade e dos teores sanguíneos de glicose, lactato, uréia, creatinina, fibrinogênio e fosfatase alcalina e do $\mathrm{pH}$ fecal foram submetidos a análise de variância com desdobramento em contrastes ortogonais utilizando-se o programa computacional Statistical Analysis System (SAS, 1989).

\section{Resultados e Discussão}

A dieta controle, com maior nível de fibra, resultou em menores $(\mathrm{P}<0,01)$ coeficientes de digestibilidade de proteína bruta, matéria orgânica e extrato etéreo $(\mathrm{P}<0,05)$ e em maiores $(\mathrm{P}<0,01)$ coeficientes de digestibilidade de FDN, FDA, hemicelulose e energia bruta (Tabela 2). A digestibilidade da matéria seca não diferiu $(\mathrm{P}>0,05)$ entre as dietas.

Os resultados de digestibilidade de proteína bruta, matéria orgânica, extrato etéreo e FDN obtidos no contraste (dieta controle $\times$ dietas-teste) estão de acordo com os relatados por Karlsson et al. (2000), que, avaliando a digestibilidade de dietas com relações feno:aveia de 100:0; 80:20; 60:40 e 40:60, observaram que a inclusão de concentrado na dieta, na forma de aveia, melhorou a digestibilidade de matéria seca, matéria orgânica, proteína bruta e energia bruta das dietas. Entretanto, a digestibilidade da FDN e FDA diminuiu e foi menor quando os animais foram alimentados com a dieta com maior nível de aveia (40:60) em comparação àquela com 100\% de feno (100:0). Resultados semelhantes foram obtidos por Drogoul et al. (2001) e Miraglia et al. (2006), ao testarem três relações de volumoso:concentrado (100:0; 70:30 e 50:50) e (100:0; 75:25 e 50:50), respectivamente. Esses autores verificaram redução no coeficiente de digestibilidade da fração fibrosa 
(FB, FDN e FDA) e hemicelulose e aumento no coeficiente de digestibilidade da MS, MO, EB e PB com o aumento da porcentagem de concentrado na dieta. De acordo com os autores, esse resultado pode ter sido decorrente da menor digestibilidade da fibra do concentrado utilizado (cevada) e do maior aporte de amido no ceco e cólon, que ocasionaram aumento das bactérias amilolíticas (Lactobacillus e Streptococcus) e redução da flora hemicelulolítica.

Os melhores resultados de digestibilidade dos componentes da fibra observados nesta pesquisa para a dietateste podem ser explicados pelo equilíbrio nutricional entre carboidratos fibrosos e não-fibrosos proporcionado pela relação 50:50 volumoso:concentrado. Esse equilíbrio possivelmente influenciou positivamente a flora bacteriana do ceco e do cólon, melhorando a digestibilidade da FDN, FDA e hemicelulose e o aproveitamento da energia bruta da dieta.

Entretanto, os menores coeficientes de digestibilidade da FDN, FDA e hemicelulose quando fornecidas as dietas com 25 e 35\% de FDN (relações 50:50 e 60:40 volumosos:concentrado) podem ter sido influenciados pela quantidade de amido consumida, que pode ter afetado a microbiota de ceco e cólon, reduzindo a ação das bactérias hemicelulolíticas, normalmente presentes em maior quantidade nesses segmentos do trato digestório, o que explica a redução na digestibilidade dos componentes da fibra quando fornecidas as dietas com menor conteúdo de fibra. Acredita-se também que a inclusão de caulin nas dietas com menor teor de fibra (25 e 35\%) pode ter contribuído para a redução da digestibili-dade da fibra. Sabe-se, no entanto, que o uso de caulin, formado por um grupo de silicatos hidratados de alumínio, é bastante difundido na indústria de rações como material inerte. É possível que esse componente tenha interagido com os componentes da dieta ou exercido efeito redutor sobre a microbiota do ceco e cólon, contribuindo para a redução dos coeficientes de digestibilidade da fibra.

As dietas com 25\% de fibra, em comparação àquelas com $35 \%$ de fibra, apresentaram melhores $(\mathrm{P}<0,01)$ de coeficientes de digestibilidade de matéria seca, matéria orgânica e energia bruta e menores coeficientes de digestibilidade de celulose $(\mathrm{P}<0,05)$ e extrato etéreo $(\mathrm{P}<0,01)$, resultados que confirmam os encontrados por Karlsson et al. (2000), Drogoul et al. (2001) e Miraglia et al. (2006), que verificaram que dietas com maior proporção de concentrado melhoram a digestibilidade de matéria seca, matéria orgânica e energia bruta. Não foram observadas diferenças $(\mathrm{P}>0,05)$ entre os níveis de 25 e 35\% FDN para os coeficientes de digestibilidade proteína bruta, FDN e FDA. Resultado semelhante foi obtido por Oliveira et al. (2003) que não encontraram diferenças para os coeficientes de digestibilidade da FDN e FDA quando utilizaram quatro proporções de volumoso e concentrado (40:60, 60:40, 80:20 e 100:00) com níveis de FDN de 37,1 a $75,7 \%$.

Os melhores resultados de digestibilidade de extrato etéreo foram obtidos quando fornecidas as dietas com $35 \%$ de FDN, o que pode estar relacionado à adição de óleo vegetal nas proporções de 4,6 e 4,9\% nas dietas com 35\% FDN (50:50 e 60:40), respectivamente, como fator de equilíbrio da energia das dietas. De acordo com Meyer (1995), fontes lipídicas de alta disponibilidade, como os óleos vegetais, podem ser totalmente digeridas e absorvidas no intestino delgado e não afetam o processo fermentativo nem a digestibilidade da fibra.

O contraste (25\% FDN 50:50 × 25\% FDN 60:40) permite comparar a fonte de fibra, ou seja, aquela proveniente do

Tabela 2 - Coeficientes de digestibilidade dos nutrientes das dietas experimentais

\begin{tabular}{|c|c|c|c|c|c|c|c|c|}
\hline \multirow[t]{2}{*}{ Dieta } & \multicolumn{8}{|c|}{ Nutriente } \\
\hline & MS & MO & PB & EB & $\mathrm{EE}$ & FDN & FDA & HCEL \\
\hline Dieta controle & 67,15 & 70,80 & 65,85 & 79,26 & 67,85 & 50,09 & 49,06 & 51,39 \\
\hline $25 \%$ FDN $60: 40$ & 71,80 & 79,07 & 70,74 & 75,85 & 45,09 & 25,51 & 24,65 & 23,70 \\
\hline $35 \%$ FDN $50: 50$ & 61,98 & 69,66 & 71,62 & 67,33 & 76,88 & 27,63 & 21,66 & 35,20 \\
\hline $35 \%$ FDN 60:40 & 61,70 & 69,07 & 70,45 & 69,92 & 79,21 & 21,51 & 21,21 & 21,62 \\
\hline Contraste $^{1}$ & 0,3148 & 0,0349 & 0,0016 & $<0,001$ & 0,0234 & $<0,001$ & $<0,001$ & $<0,001$ \\
\hline Contraste $^{2}$ & $<0,001$ & $<0,001$ & 0,0935 & 0,001 & $<0,001$ & 0,1920 & 0,1866 & 0,0439 \\
\hline Contraste $^{3}$ & 0,0251 & 0,0077 & 0,0540 & 0,0136 & 0,2954 & 0,0272 & 0,0010 & 0,6401 \\
\hline Contraste $^{4}$ & 0,8783 & 0,6539 & 0,4066 & 0,0778 & 0,5216 & 0,0933 & 0,8735 & 0,0021 \\
\hline CV (\%) & 4,22 & 2,77 & 3,08 & 2,90 & 8,99 & 18,72 & 16,90 & 17,89 \\
\hline
\end{tabular}

1 Dieta controle $\times$ dietas-teste.

2 25\% FDN 50:50 + 25\% FDN 60:40 × 35\%FDN 50:50 + 35\% FDN 60:40

$325 \%$ FDN 50:50 × 25\% FDN 60:40.

4 35\% FDN 50:50 × 35\% FDN 60:40. 
volumoso ou concentrado, quando a FDN é limitada em $25 \%$. Portanto, a dieta com relação volumoso:concentrado 60:40 melhorou a digestibilidade aparente de matéria orgânica e FDA $(\mathrm{P}<0,01)$, matéria seca, proteína bruta, energia bruta e FDN $(\mathrm{P}<0,05)$ em comparação àquela com relação 50:50, todavia, não ocasionou diferenças $(P>0,05)$ na digestibilidade de hemicelulose e extrato etéreo. Esperava-se que a dieta com maior porcentagem de concentrado (50:50) melhorasse os coeficientes de digestibilidade de matéria seca, matéria orgânica, proteína bruta, energia bruta e extrato etéreo e que aquela com maior porcentagem de feno (60:40) promovesse melhores coeficientes de digestibilidade da fibra, conforme relatado por Drogoul et al. (2001) e Miraglia etal.(2006). Os melhores resultados de digestibilidade da FDN e FDA obtidos com as dietas com maior porcentagem de fibra, 25\% de FDN (60:40), reforçam os relatos de Zeyner et al. (2004), que observaram melhora na atividade microbiana no ceco e cólon e tendência de os microrganismos fermentadores de celulose trabalharem mais eficientemente com a inclusão de feno na dieta.

Não foi constatada influência das relações volumoso:concentrado (50:50 e 60:40) sobre os coeficientes de digestibilidade de matéria seca, matéria orgânica, proteína bruta, FDN, FDA, energia bruta e extrato etéreo $(\mathrm{P}>0,05)$. No entanto, a dieta com maior proporção de concentrado (35\% FDN, 50:50) melhorou $(\mathrm{P}<0,01)$ a digestibilidade da hemicelulose. Esperava-se que a dieta com maior porcentagem de concentrado (35\% FDN 50:50) proporcionasse melhora na digestibilidade de matéria seca, proteína bruta, matéria orgânica, energia bruta e extrato etéreo e que a dieta com maior porcentagem de volumoso (35\% FDN, 60:40) promovesse melhora na digestibilidade dos componentes da fibra (Karlsson et al., 2000; Drogoul et al., 2001; Miraglia et al., 2006). Entretanto, a origem da fibra, do volumoso ou do concentrado e as duas proporções testadas não promoveram diferenças na digestibilidade desses nutrientes. Por outro lado, o equilíbrio dos carboidratos fibrosos e não-fibrosos nas duas dietas foi adequado para o crescimento das bactérias celulóticas, uma vez que a digestibilidade da fibra não foi afetada. As condições para ação da flora celulolítica no ambiente do ceco e cólon possivelmente contribuiu para a melhora da digestibilidade da hemicelulose da dieta com maior porcentagem de concentrado (35\% FDN 50:50), cuja quantidade desse nutriente era maior.

Os níveis de fibra da dieta não influenciaram os níveis sangüíneos de glicose e lactato nem o pH fecal ( $\mathrm{P}>0,05)$ (Tabela 3), parâmetros indicativos de alteração das condições do ambiente do intestino grosso. O consumo limitado de carboidratos fibrosos, combinado a maior ingestão de
Tabela 3 - pH fecal e níveis sangüíneos de glicose e lactato sangüíneo em eqüinos alimentados com dietas experimentais

\begin{tabular}{lccc}
\hline Dieta & pH fecal & Glicose $(\mathrm{mg} / \mathrm{dL})$ & Lactato $(\mathrm{mmol} / \mathrm{L})$ \\
\hline Controle & 6,15 & 66,99 & 2,60 \\
25\% FDN 50:50 & 6,08 & 69,18 & 2,62 \\
25\% FDN 60:40 & 6,24 & 69,36 & 2,47 \\
35\% FDN 50:50 & 6,29 & 68,37 & 2,55 \\
35\% FDN 60:40 & 6,26 & 65,59 & 2,13 \\
\hline Contraste & \multicolumn{3}{|}{} \\
\hline Contraste & 0,5147 & 0,4729 & 0,5275 \\
Contraste $^{2}$ & 0,2117 & 0,1216 & 0,3695 \\
Contraste $^{3}$ & 0,2225 & 0,9270 & 0,6370 \\
Contraste $^{4}$ & 0,8013 & 0,1779 & 0,2078 \\
CV $(\%)$ & 3,16 & 4,52 & 20,04 \\
\hline
\end{tabular}

1 Dieta controle $\times$ dietas-teste.

2 25\% FDN 50:50 + 25\% FDN 60:40 × 35\%FDN 50:50 + 35\% FDN 60:40. $325 \%$ FDN 50:50 $\times 25 \%$ FDN 60:40.

$435 \%$ FDN 50:50 × 35\% FDN 60:40.

carboidratos não-fibrosos, como amido, pode aumentar a produção de ácido lático no ceco e cólon. Segundo Hoffman (2003), parte do ácido lático produzido é absorvida e pode alterar os níveis plasmáticos deste ácido. Parte do ácido lático presente no ceco e cólon pode promover redução do pH do ambiente, causando lise de bactérias e aumentando o risco de endotoxemia e laminite.

Não foram observadas diferenças entre as dietas com menor nível de fibra (25 e 35\%) nem tendências de redução dos valores do pH fecal e aumento dos níveis sangüíneos de lactato, que se mantiveram nos limites fisiológicos normais (Swenson et al., 1993). O valor do pH médio obtido com as cinco dietas não foi crítico para o intestino grosso ( $\mathrm{pH}$ maior que 6), uma vez que $\mathrm{pH}$ igual ou menor que 5 pode causar lesões na mucosa do intestino (Swenson et al., 1993). Portanto, os teores de fibra testados nas dietas e as relações volumoso:concentrado são nutricionalmente seguros se avaliados quanto aos aspectos bioquímicos.

Os níveis de glicose podem ser influenciados pelas características da dieta. Dietas ricas em grãos tendem a promover melhor digestão dos carboidratos não-fibrosos, como amido, no intestino delgado e maior aporte de glicose sangüínea, enquanto dietas ricas em fibra resultam em maior conversão dos carboidratos fibrosos em ácidos graxos voláteis no ceco e cólon (Cunha, 1991). Dietas ricas em carboidratos não-fibrosos também tendem a aumentar a produção de propionato no ceco e cólon. Evidências em pôneis indicam que cerca de 7\% da glicose sangüínea é derivada do propionato produzido no ceco (Frape, 2004).

Como o ácido propiônico é precursor de glicose, esperava-se que os resultados obtidos proporcionassem maior disponibilidade de glicose sanguínea nas dietas com menor 
teor de fibra (25 e 35\%). Entretanto, os resultados obtidos para glicose sanguínea não diferiram entre as dietas $(\mathrm{P}>0,05)$, provavelmente em virtude da resposta insulínica, uma vez que a coleta das amostras ocorreu aproximadamente 12 horas após a última alimentação, o que pode ter inibido os resultados de glicose sanguínea, apesar da ligeira tendência de aumento nos animais alimentados com a dieta contendo $25 \%$ de FDN . Casalecchi (2003), em estudo para verificar os efeitos do processamento do milho (triturado, laminado, floculado e extrusado) na digestibilidade e nos níveis plasmáticos de glicose em eqüinos alimentados com $50 \%$ de feno de tifton e $50 \%$ de concentrado (milho processado), verificou que o pico sanguíneo de glicose ocorreu 30 minutos após a administração da ração e retornou aos valores basais 150 minutos após a alimentação, possivelmente em razão da resposta insulínica. De acordo com Frape (2004), a concentração de glicose plasmática aumenta sensivelmente após a alimentação e retorna aos níveis basais em torno de 5 horas após a alimentação, como resultado da regulação hormonal.

Os níveis séricos de glicose encontrados nesta pesquisa foram inferiores aos observados por Casalecchi (2003), de 82 a $97 \mathrm{mg} / \mathrm{dL}$, em animais em jejum por 10 horas; e daqueles descritos por Meyer (1995a), de 75 a 115 mg/dL. Todavia, os resultados se aproximaram dos encontrados por Mori et al. (2003) em grupo amostral de asininos em condições de campo, 58,35 $\pm 10,40 \mathrm{mg} / \mathrm{dL}$.

Os níveis séricos de uréia e creatinina estão relacionados às funções fisiológicas normais do sistema visceral (fígado e vísceras drenadas pela veia porta) e dos rins (Kozloski, 2001). Segundo Meyer (1995a), os teores de creatinina podem ser influenciados por lesões no fígado, nos rins e no trato urinário. De acordo com Grulke et al. (2001), níveis de uréia superiores a $40 \mathrm{mg} / \mathrm{dL}$ podem estar relacionados ao grau de severidade e ao prognóstico da cólica eqüina, entretanto, quando atingem esses valores, verificam-se sinais clínicos, como dor, distensão abdominal e borborígnos. Portanto, a uréia torna-se ineficiente como indicador precoce de cólica em eqüinos. Contudo, as dietas utilizadas nesta pesquisa foram formuladas para atender às exigências diárias dos cavalos e permitir o consumo eqüitativo de proteína (NRC, 1989), logo, os níveis séricos de uréia confirmam o consumo eqüitativo de proteína pelos animais, uma vez que as dietas foram isoprotéicas.

Entre as dietas, não houve diferença nos níveis séricos de uréia e creatinina. Portanto, os níveis de 25 e 35\% de FDN não comprometeram o sistema visceral e os rins dos animais. Os níveis séricos de uréia foram próximos aos observados por Mori et al. (2003) em asininos $(24,25 \pm 5,37 \mathrm{mg} / \mathrm{dL})$ e os de creatinina, próximos dos limites fisiológicos descritos por Meyer(1995a), de 1,2 a 1,9 mg/dL. Durante o experimento, não foram observados sinais clínicos que indicassem quadro clínico de cólica ou doença renal, logo, os níveis séricos de uréia e creatinina mantiveram-se dentro do esperado e não foram influenciados pelos níveis de fibra da dieta.

O fibrinogênio sérico - polipeptídio complexo do grupo das proteínas conhecidas como de reação de fase aguda, produzido pelo fígado - foi influenciado $(\mathrm{P}<0,05)$ pelos níveis de fibra da dieta. Além de sua importância primária como proteína de coagulação, o fibrinogênio aumenta em todas as situações que envolvem dano celular, infecção, inflamações teciduais e na gestação (Campos, 2003). De acordo com Meyer (1995a), o fibrinogênio é um indicador sensível de inflamação em animais herbívoros e pode ser mais preciso que o leucograma. De acordo com Thomassian (1994), o fibrinogênio é um componente importante na síndrome cólica, pois é o primeiro a aumentar e o último a reduzir e pode ser reduzido nas alterações hepáticas. Ao diminuir o nível de fibra da dieta de 35\% para $25 \%$, houve aumento na produção de fibrinogênio, logo, mesmo que não tenha desencadeado manifestações clínicas, o nível de $25 \%$ de FDN causou elevação na produção de fibrinogênio. Os animais alimentados com as dietas com 35\% de FDN apresentaram valores inferiores aos limites fisiológicos relatados por Meyer (1995a) e Swenson (1993), de 200 a $400 \mathrm{mg} / \mathrm{dL}$, entretanto, foram superiores ao valor de $100 \mathrm{mg} / \mathrm{dL}$, considerado crítico por Garcia-Navarro \& Pachaly (1994) para desencadear sinais clínicos.

A fosfatase alcalina não foi influenciada $(\mathrm{P}>0,05)$ pelos níveis de fibra da dieta. Essa enzima está associada às lesões de origem hepatobiliar (Meyer, 1995a), cuja variação sérica pode indicar processo de cólica (Frape, 1992). Nesta pesquisa, avaliaram-se os níveis séricos de fosfatase alcalina como possível indicador de cólica, em razão dos baixos níveis de fibra utilizados. O teor de fosfatase alcalina poderia indicar também desenvolvimento de doença hepática durante o período de pesquisa. Entretanto, as concentrações desta enzima não indicaram tendência de aumento quando fornecidas as dietas com menor nível de fibra e se mantiveram dentro dos limites fisiológicos relatados por Merk (1997), de 70 a 226 UI/L. Possivelmente, os níveis de fibra utilizados nesta pesquisa não foram críticos para os animais e não ocasionaram, portanto, manifestação clínica de cólica ou de doença hepática que resultasse em alterações detectáveis dos níveis de fosfatase alcalina. 
Tabela 4 - Níveis séricos de uréia, creatinina, fibrinogênio e fosfatase alcalina em eqüinos alimentados com as dietas experimentais

\begin{tabular}{lcccc}
\hline Dieta & Uréia $(\mathrm{mg} / \mathrm{dL})$ & Creatinina $(\mathrm{mg} / \mathrm{dL})$ & Fibrinogênio $(\mathrm{mg} / \mathrm{dL})$ & Fosfatase alcalina $(\mathrm{UI} / \mathrm{L})$ \\
\hline Controle & 25,34 & 1,23 & 216,23 & 88,91 \\
$25 \%$ FDN 50:50 & 25,98 & 1,16 & 266,40 & 89,85 \\
$25 \%$ FDN 60:40 & 26,72 & 1,20 & 231,56 & 88,43 \\
$35 \%$ FDN 50:50 & 27,12 & 1,18 & 90,75 \\
$35 \%$ FDN 60:40 & 25,63 & 1,23 & 190,84 & 88,49 \\
\hline Contraste & & & & $0,766,63$ \\
\hline Contraste & & & 0,9469 & 0,7283 \\
Contraste $^{2}$ & 0,7438 & 0,4488 & 0,0325 & 0,4702 \\
Contraste $^{3}$ & 0,9712 & 0,9831 & 0,4409 & 0,2503 \\
Contraste $^{4}$ & 0,6133 & 0,4540 & 0,5914 & 4,84 \\
CV $(\%)$ & 0,3245 & 0,8375 & 46,64 &
\end{tabular}

${ }^{1}$ Dieta controle $\times$ dietas-teste.

2 25\% FDN 50:50 + 25\% FDN 60:40 × 35\%FDN 50:50 + 35\% FDN 60:40

$325 \%$ FDN 50:50 $\times 25 \%$ FDN 60:40.

$435 \%$ FDN 50:50 × 35\% FDN 60:40.

\section{Conclusões}

Dietas com 25 e $35 \%$ de fibra em detergente neutro oriundas de duas proporções de volumoso e concentrado, 50:50 e 60:40, reduzem a digestibilidade dos componentes fibrosos e não influenciam os níveis séricos de glicose, lactato, uréia, creatinina e fosfatase alcalina. No entanto, dietas com 25\% de fibra em detergente neutro promovem alteração no teor plasmático de fibrinogênio, podendo aumentar a predisposição dos eqüinos a quadros de laminite e cólica.

\section{Literatura Citada}

CAMPOS, S. [2003]. Diagnóstico e Laboratório. Idelco Ltda. Disponível em: <http://www.drashirleydecampos.com.br/noticias. php?noticiaid=7791\&assunto=Diagn\%C3\%B3stico\% 20e\%20l aborat\%C3\%B3rio> Acesso em: 3/5/2007.

CASALECCHI, F.L. Digestibilidade aparente total de dietas com milho submetido a diferentes processamentos e resposta glicêmica em eqüinos. Pirassununga: Universidade de São Paulo, 2003. 48p. Dissertação (Mestrado em Nutrição Animal) - Universidade de São Paulo, 2003.

CUNHA, T.J. Horse feeding and nutrition. 2.ed. London: Academy Press, 1991. 445p.

DROGOUL, C.; FOMBELle, A.; JULLiAnD, V. Feeding and Microbial disorders in horses: 2. Effect of three hay:grain ratios on digesta passage rate an digestibility in ponies. Journal of Equine Veterinary Science, v.21, n.10, p.487491, 2001.

FRAPE, D.L. Nutrición y alimentación del caballo. Zaragoza: Acribia, 1992. 404p.

FRAPE, D.L. Equine nutrition and feeding. Boston: Blackwell Publishing, 2004. 664p.

GARCIA-NAVARRO, K.C.E.; PACHALY, J.R. Interpretação do hemograma. Manual de hematologia veterinária. 1.ed. São Paulo: Varela, 1994a. p.94-95.

GRULKE, S.; OLLE, E.; DETILLEUX, J. et al. Determination of a gravity and shock score for prognosis in equine surgical colic. Journal of Veterinary Medicine, v.48A, p.465-473, 2001.
HOFFMAN, R.M. [2003]. Carbohydrate metabolism in horses. In: TALSTON, S.L.; HINTZ, H.F. (Eds). Recent advances in equine nutrition. Ithaca: International Veterinary Information Service, 2003. Disponível em: <http://<www.ivis.org > Acesso em: $12 / 1 / 2006$.

KANEKO, J.J. Clinical biochemistry of domestic animals. 4.ed. San Diego: Academic Press, 1989. 932p.

KARLSSON, C.P.; LINDBERG, J.E.; RUNDGREN, M. Associative effects on total tract digestibility in horses fed different ratios of grass hay and whole oats. Livestock Production Science. v.65, p.143-153, 2000.

KLINE, K.H. Horse feeds and feeding. Feedstuffs, v.68, n.30, p.75-78, 1996.

KOZLOSKI, G.V.; ROCHA, J.B.T.; CIOCCA, M.L.S. Metabolismo visceral e eficiência do uso da energia pelos ruminantes. Ciência Rural, v.31, n.5, p.909-915, 2001.

MANUAL MERCK DE VETERINÁRIA. Manual de diagnóstico, tratamento, prevenção e controle de doenças para veterinário. 7.ed. São Paulo: Roca, 1996. 2169p.

MEYER, D.J. Medicina de laboratório veterinária: interpretação e diagnóstico. São Paulo: Roca, 1995. 308p.

MEYER, H.; COENEN, M.; GURER, C. Investigations of saliva production and chewing in horses fed various feeds. In: EQUINE NUTRITION AND PHYSIOLOGY SYMPOSIUM, 9., 1985, Michigan. Proceedings... Michigan, 1985. p.38.

MEYER, H. Alimentação de cavalos. São Paulo: Varela, 1995 303p.

MIRAGLIA, N.; BERGERO, D.; POLIDORI, M. et al. The effects of a new fibre-rich concentrate on the digestibility of horse rations. Livestock Science, v.100, p.10-13, 2006.

MORI, E; FERNANDES, W.R.; MIRANBOLA, R.M.S. Reference values on serum biochemical parameters of Brazilian donkey (Equus asinus) breed. Journal of Equine Veterinary Science, v.23, n.8, p.358-364, 2003.

NATIONAL RESEARCH COUNCIL - NRC. Nutrient requeriments of horses. 5.ed.rev. Washington, D.C.: Academy Press, 1989. $100 \mathrm{p}$.

OLIVEIRA, C.A.A.; ALMEIDA, F.Q.; VALADARES FILHO, S.C. et al. Estimativa da digestibilidade aparente de nutrientes em dietas para eqüinos, com o uso de óxido crômico e indicadores internos. Revista Brazileira de Zootecnia, v.32, n.6, p.16811689, 2003.

PAGAN, J.D. Forages for horses: more than just a filler. Equine neurology and nutrition. In: BAIN-FALLON MEMORIAL LECTURES, 8., 1996, Glenelg. Proceedings... Glenelgp: 1996. p.189-205. 
PAGAN, J.D. Carbohydrates in equine nutrition. Feed Mix, v.7, n.4, p.9-12, 1999.

STATISTICAL ANALYSIS SYSTEM - SAS. SAS/STAT ${ }^{\circledR}$ user'guide: version 6. 5.ed. Cary: 1989. v.2, 846p.

SILVA, D.J. Análise de alimentos (métodos químicos e biológicos). Viçosa, MG: Universidade Federal de Viçosa, 1990. 165p.

SWENSON, M.J.; REECE, W.O. Dukes - Fisiologia dos animais domésticos. Guanabara Koogan: Cornell University, 1993. 856p.

THOMASSIAN, A. Complicações pós-operatórias e prognostico a longo prazo em 32 casos cirúrgicos de cólica eqüina. In: CONGRESSO BRASILEIRO DE CIRURGIA E ANESTESIOLOGIA VETERINARIA, 1., 1994, Curitiba. Anais... Curitiba: 1994. p.45-46.
Van SOEST, P.J. Development of a comprrehensive sytem of feed analyses and its application to forages. Journal of Animal Science, v.26, n.1, p.119-128, 1967.

Van SOEST, P.J.; ROBERTSON, J.B.; LEWIS, B.A. Methods for dietary fiber, neutral detergent fiber, and nonstrach plysaccharides in relation to animal nutrition. Journal of Dairy Science, v.74, p.3583-3597, 1991.

ZEYNER, A.; GEIBLER, C.; DITTRICH, A. Effects of hay intake and feeding sequence on variables in faeces and fecal water (dry matter, $\mathrm{pH}$ value, organic acids, ammonia, buffering capacity of horses). Journal Animal Physiology and Animal Nutrition, v.88, p.7-19, 2004. 